\title{
LA SOMBRA DE HEIDEGGER Y NIETZSCHE: RECORDANDO A FRANCO VOLPI (1952-2009)
}

\author{
Heidegger's and Nietzsche's Shadow: \\ Remembering Franco Volpi (1952-2009) \\ Giuliano Campioni - Franco Volpi \\ Universidad de Pisa - Universidad de Padua
}

\begin{abstract}
Resumen: La influencia de Nietzsche en el pensamiento de Heidegger es notoria. Tal vez uno de los filósofos que con más perspicacia ha señalado ese impacto de una manera lúcida y sin estridencias haya sido Franco Volpi. Poco antes de morir, y con motivo de la publicación de la traducción italiana de la obra de Heidegger Contribuciones a la filosofía, dejaba clara su posición frente a Heidegger, interpretando de una manera crítica, pero ecuánime, el gran peso de la filosofía de Nietzsche en su camino del pensar. Este juicio de Volpi da que pensar y nos obliga a reflexionar sobre la filosofía de Heidegger sin perder de vista la zozobra que experimentó su filosofía en el «mar del Ser» ante el impacto que produjo en sus mamparas el reto nunca superado de la filosofía de Nietzsche.
\end{abstract}

Aвstract: The influence of Nietzsche on Heidegger's thought is evident. Perhaps one of the most insightful philosophers that have noted this impact in a lucid manner was Franco Volpi. Shortly before his death, and to mark the publication of the Italian translation of Heidegger's work Contributions to philosophy, he made clear his position about Heidegger, interpreting in a critical but fair way the great weight of the philosophy of Nietzsche in Heidegger's path of thinking. This judgement is thought-provoking and forces us to reflect on Heidegger's philosophy without losing sight of the uneasiness of his philosophy in the «sea of Being», because of the impact made on its screens by the challenge, never overcome, of Nietzsche's philosophy.

Se publican en este número dos escritos de Franco Volpi, desaparecido trágicamente el 14 de abril de 2009 en un accidente de carretera: la entrevista «Heidegger e la sua ombra» (mayo de 1988), realizada por Giovani Gurisatti, su amigo y colaborador, publicada en la revista local Porto Franco, y el artículo «I lumi e l'ombra lunga di Nietzsche», publicado en el diario La Repubblica, el 8 de diciembre de 2000. Cuando se publicó la entrevista, Volpi tenía como activo sobre Heidegger varios ensayos y monografías: L'aristotelismo e il problema dell'univocità dell'essere nella formazione del giovane Martin Heidegger (Padova: Cedam, 1976) y Heidegger e Aristotele (Padova: Daphne, 1984). Además había comenzado su importante trabajo editorial en las ediciones Adelphi con la traducción de Segnavia (Wegmarken) [en español Hitos] y estaba preparando otros escritos de Heidegger entre los que era central la traducción de Nietzsche, que vería la luz en 1994. El segundo escrito es la intervención de Volpi el 8 de diciembre de 2000 en La Repubblica —en el que colaboraba en la sección cultural desde 1992- en el debate sobre el tema Chè cosa significa oggi essere illuministi, nacido del artículo 
de Eugenio Scalfari, que se publica en el mismo diario el 3 de diciembre con el título «I lumi del nostro secolo non sono più di moda». La discusión atrajo a participar a muchas autoridades filosóficas italianas: Sebastiano Maffettone (30 de diciembre), Umberto Eco (31 de diciembre), Sergio Givone (2 de enero de 2001), Gianni Vattimo (4 de enero), Roberto Esposito (6 de enero), Sergio Moravia (10 de enero), Carlo Bernardini (12 de enero), Giancarlo Bosetti (18 de enero), Norberto Bobbio (25 de enero) y Ralf Dahrendorf (31 de enero).

Agradecemos a la mujer de Franco Volpi, Ruth Otte, y a su hija, Laura Volpi, que hayan autorizado cortésmente la publicación de los dos textos.

\section{FRANCO VOLPI: DE HEIDEGGER A NIETZSCHE. PARA LA CONSTRUCCIÓN DE UN NUEVO ETHOS FILOSÓFICO ${ }^{1}$}

\section{Giuliano Campioni \\ Universidad de Pisa}

Esta pequeña introducción quiere recordar momentos del trabajo de Franco Volpi, un gran amigo y un punto de referencia claro y continuo para un diálogo e investigación sobre temas comunes. Algunos días anteriores al trágico accidente, habíamos hablado de su último artículo en La Repubblica del viernes santo sobre Nietzsche, en el que Franco comentaba las frases de Benedicto XVI, que el día anterior, en su homilía, había estigmatizado el pensamiento del filósofo, que a los ojos del pontífice representaba la «soberbia destructiva y la presunción que disgregan cualquier comunidad y terminan en la violencia». Según Ratzinger, los peores males de la época se remontan al filósofo alemán, y son generados por su relativismo. «Pobre Nietzsche! Ha sido el único filósofo al que le ha tocado el singular privilegio de ser considerado responsable nada menos que de una guerra mundial», era el incipit de la intervención.

Durante el conflicto de 1914-1918 estaban expuestos en el escaparte de una librería de Picadilly los dieciocho volúmenes de sus obras completas en inglés, con una inscripción en letras cubitales: The Euro-Nietzschean-War: leggete il diavolo per poterlo combattere meglio! [iLeed al diablo para poderlo combatir mejor!].

Se trataba de la edición de Oscar Levy, judío alemán emigrante, cosmopolita, médico, convertido en experto filólogo que, en conflicto radical con Elisabeth («doméstica pequeño-burguesa») y con el Archivo de Weimar, centro de irradiación de la leyenda y del culto, defendía la integridad de los textos y de la imagen cosmopolita de Nietzsche.

En la afirmación de Volpi se advierte uno de los aspectos peculiares de su forma de proceder: la capacidad inmediata de trasmitir plásticamente, con clari-

1. Traducimos, con algunas modificaciones, el texto de la ponencia de Giuliano Campioni «Franco Volpi interprete di Nietzsche e Schopenhauer», en el «Encuentro Internacional de estudios, Franco Volpi intérprete del pensamiento contemporáneo», Universidad de Padua, Fondazione Collegio san Carlo di Modena, Padua, 19 de noviembre de 2009. 
dad, a través de un episodio significativo, a través de una anécdota y una imagen, un problema importante, el sentido de una situación histórico-cultural. Aquel día habíamos hablado también del significado de nuestra inminente iniciativa con Eugenio Scalfari — prevista para el 6 de mayo-para volver a proponer, en un diálogo dirigido a un amplio público, aquel Nietzsche que nos era común y querido, basado en la complejidad y complexividad de los textos filológicamente establecidos, con el sentido de la fuerza devastadora de sus análisis y de sus lecturas «diferidas» del Novecento, un Nietzsche, por lo tanto, lejos de las simplificaciones ideológicas y llenas de prejuicios —en un sentido y en el otro- que tienden siempre a ir adelante como signo de los tiempos.

Significativa a tal propósito es la respuesta a quien «armado de ideología ha ya predeterminado sus conclusiones y sus víctimas», o sea, el filósofo Nietzsche y aquellos que, queriendo solapadamente enmascarar la culpabilidad y reconstruir la virginidad, se habrían vuelto a su vez «doblemente y obstinadamente» culpables. Somos arrastrados por la historia sin tantos pasos al tribunal. Escribía:

Un tribunal fundamentalista en el que sienta como imputado a Nietzsche y, junto a él, a Colli y Montinari. Así, más que una reconstrucción científica conducida sine ira et studio parece tener bajo su mirada el acto final de un proceso de inquisición [...]. El historiador que se obstina en querer comprender más de aquello que hay que comprender comprende menos de todo.

Una concepción de la historia, la de Volpi, en las antípodas de toda ideología que procesa y que, en nombre de valores inconcusos, condena y no comprende: que cambia por lo tanto el síntoma y el diagnóstico con la causa. Recientemente hizo valer su libertad frente a las críticas prejuiciosas lanzadas por los «campeones de la hipocresía» contra Carl Schmitt, de quien ha publicado y comentado magistralmente el importante texto filosófico La tirannia dei valori (Adelphi, 2008). Volpi valora en este escrito la capacidad de poner en guardia contra

la inclinación hacia el conflicto ideológico ínsito en el reclamo de los valores [...] No es un problema el ser de los valores, sino su realización: porque conduce al fundamentalismo, al fanatismo y al terrorismo de la virtud. Como ironiza Schmitt, el pensar por medio de valores — sobre la base del principio de que el fin justifica los medios- «consiente en pagar mal con mal, trasformando así nuestra tierra en un infierno, pero el infierno en un paraíso de valores».

Tal actitud y estilo en la investigación la ha hecho valer Franco para autores que diagnostican con radicalidad la crisis de nuestro tiempo: su volumen dedicado a Il nichilismo (1996) ${ }^{2}$, que ha tenido un justo reconocimiento internacional, constituye la síntesis de estas investigaciones suyas, amplias y variadas.

Nuestra relación de amistad y colaboración nace en 1992, en torno al filósofo alemán, cuando nos encontrábamos juntos para criticar una llamativa edición italiana de la Voluntad de poder — la compilación desmañada de Elisabeth y Peter Gast- que se acompañaba, por los editores, de una pretendida y decidida desacreditación de los resultados de la edición crítica de Colli y Montinari, para

2. F. Volpi, El nihilismo, Madrid: Siruela, 2008. 
Volpi «una de las empresas filológicas más notables de nuestro siglo y un mérito para la cultura italiana». Con la acostumbrada claridad y precisión, desmontaba el sentido de una improvisada e impróvida operación editorial dirigida sustancialmente a volver a proponer un Nietzsche pre-nazi: la publicación podía tener alguna justificación sólo si la Voluntad de poder (insostenible filológicamente y denunciada con fuerza también por Heidegger) se hubiese presentado con un aparato y un comentario adecuados, que evidenciasen su carácter históricodocumental. Tanto más cuanto los partidarios de la Wille zur Macht se remitían a la autoridad de Heidegger: aquel era el texto que Heidegger había conocido y sobre el que había trabajado y, por lo tanto, como tal era propuesto de nuevo. Pero Volpi mostró, sobre la base de los estudios que hacía también para la traducción del Nietzsche, cómo incluso Heidegger había insistido críticamente sobre la estrechez de la elección, sobre la mala compilación y distribución de los fragmentos, o bien —como dirá Heidegger en 1939- que se trataba de una incauta «fabricación a posteriori» de una obra que Nietzsche no había escrito nunca como tal. Volpi analizaba con seguridad filológica e histórica los límites y la insostenibilidad de esta obra:

Aludo sólo a algunas de las infinitas dudas que el texto despierta: ¿por qué en la primera edición sólo 483 fragmentos y luego, por el contrario, 1067? ¿Y por qué en la segunda edición desaparecen 17 fragmentos de la primera? Además, ¿̇por qué en la edición definitiva 25 textos conexos entre sí son desmembrados y convertidos en 55 , entre ellos el gran fragmento sobre el nihilismo, fechado por Nietzsche «Lenzer Heide, 10-6-1887»? En la Voluntad de poder este fragmento, filosóficamente importantísimo, se desmiembra en los fragmentos números 4, 5, 114 y 55 (por lo tanto, hay que leer en esta sucesión) y sólo en la edición de Colli-Montinari lo tenemos de nuevo en su forma originaria (vol. VIII, tomo I, pp. 199-206). He aquí un ejemplo en el que Colli y Montinari han hecho una contribución filológica indispensable para la interpretación filosófica. Y sin embargo, ¿̇por qué asumir como criterio para la distribución de los fragmentos un solo plan, el de Niza de marzo de 1887, y no otros entre los numerosos que Nietzsche redacta? ¿Y por qué mezclar sistemáticamente fragmentos de periodos diversos? Y, finalmente, ¿̇por qué casar todos aquellos fragmentos que sólo Colli-Montinari nos permiten leer hoy ${ }^{3}$ ?

Volpi mostraba cómo Heidegger, al investigar el tema central del eterno retorno, se encontró con graves dificultades con la compilación de Elisabeth, que no permite percibir los cambios entre 1881 y la segunda mitad de los años ochenta.

Presupuesto necesario para darse cuenta de este cambio - escribía Heidegger- es que no se acepte a la ligera la disposición de los quince fragmentos tal y como se encuentran en la edición hoy disponible, sino que se los ordene según su sucesión cronológica. En el agrupamiento actual los fragmentos son dejados desordenadamente, el primero se remonta a 1884, el último, que termina el conjunto de la obra, se remonta a 1885 , mientras que es inmediatamente precedido por un fragmento tardío, del último año, de 1888. Establezcamos ante todo el orden cronológico de los apuntes.

3. La Repubblica, 29 de noviembre de 1992. 
Heidegger buscaba arreglárselas de la mejor manera sobre la base de los indicios de la edición de 1911 para reordenar lo que podía y como podía.

Volpi había estudiado a fondo la actividad de Heidegger en el Archivo de Weimar con vistas a una «nueva edición» de la Wille zur Macht, publicando también la importante carta inédita del 26 de diciembre de 1942 en la que el filósofo, dejando el comité científico para la edición histórico-crítica, afirmaba haber ultimado «los trabajos preliminares para la edición de la Voluntad de poder, que duraron años». A Ernesto Grassi le revelará que había destruido los apuntes para la nueva sistematización del material póstumo. En realidad, no conseguiremos comprender cuál podría ser la nueva Voluntad de poder que Heidegger preparaba, dado que la única manera para «publicarla» es la de negarla, la de deshacer los materiales de la compilación (apuntes preparatorios y esbozos, reflexiones originales, pero también excerpta de lecturas, etc.) recolocándolos en el interior de los cuadernos restituidos en su integridad según el orden cronológico (como lo ha hecho la edición Colli-Montinari).

Cuando intervino conmigo en la polémica contra aquella edición de la Voluntad de poder, Volpi estaba trabajando en la traducción del Nietzsche de Heidegger, que saldría en 1994 después de un trabajo de más de diez años. Luego ha contado cómo a las iniciales perplejidades de Roberto Calasso, director editorial de Adelphi, por la dimensión del trabajo («Usted es muy joven, ¿̇traduciría mil páginas de Heidegger?»), había respondido que «sólo siendo joven está uno inclinado a las locuras. Fuimos juntos a ver al editor alemán Neske y se llegó a un acuerdo ${ }^{4}$. La publicación fue programada en el marco de la edición adelphiana de otras importantes obras de Heidegger, traducidas por Volpi y casi seguidas, que aparecieron todavía antes que Nietzsche: Segnavia (1987), La poesia di Hölderlin (1988), el diálogo con Jünger Oltre la linea (1989), Il principio di ragione (1991) y los Seminari (1992). En total cerca de diez años de trabajo, al final de los cuales llega también el texto sobre Nietzsche. La edición de Volpi ha corregido una serie de erratas y errores, también graves, del original, y ha sacado a la luz material inédito precioso para la reconstrucción de la génesis de la obra. Además, para cada referencia y cita de Nietzsche, Volpi ha dado —-sirviéndose también de mi colaboración - la concordancia con la edición Colli-Montinari, haciendo posible al lector la confrontación con los textos corregidos, el conocimiento del contexto en que estos textos se encuentran y su colocación cronológica. La publicación de Segnavia (Wegmarken) [Hitos], marca por competencia y rigor un giro decisivo en los estudios heideggerianos. Su traducción afronta las conocidas dificultades del lenguaje filosófico, con su «etimología especulativa», alejándose de los esoterismos y de «adornar cada página de expresiones alemanas», creando neologismos abstrusos. El glosario que acompaña a la impracticable traducción de este "chamán de la palabra» (así definía Volpi a Heidegger en una entrevista de 1988) «representa un pequeño monumento de precisión, claridad, competencia», como escribe Cacciari, que define a Volpi como un «filósofo de la traducción». «Saber escuchar y traducir. Más aun, saberse expresar y traducirse, y ser capaz de traducir lo consigue quien tiene pasión por la profundidad abismal de la palabra. En Volpi filosofía y filología vuelven a su afinidad

4. La Repubblica, 16 de octubre de 1994. 
de gustos ${ }^{5}$. Los ensayos que acompañan a las numerosas obras de Heidegger editadas por él son una verdadera y auténtica vía — puntual y segura- en el complejo trayecto del filósofo.

El rigor filológico y la conciencia histórica y crítica de Volpi, ligados a la lección de maestros como Giuseppe Faggin (en el liceo de Vicenza) y de Enrico Berti (en la Universidad de Padua), han tenido una manera de manifestarse plenamente, al comienzo, en sus trabajos sobre Heidegger e Brentano (1976) y Heidegger e Aristotele (1984), ensayos que marcan una relevante novedad en el acercamiento al filósofo alemán que «representa en nuestro siglo lo que Hegel había representado en el siglo XIX». Ciertamente el punto de partida para la lectura de Nietzsche ha sido Heidegger pero no, como veremos, el punto de llegada: además, el Nietzsche de Volpi (y también el de Heidegger) está lejos de la escolástica heideggeriana, a menudo estéril. Volpi saca a la luz el duro aferrarse durante largos años a los dos, la apretada confrontación «que restituyó el vértigo de hacer filosofía en gran estilo", pero que no consigue resolver el enigma Nietzsche. Desde 1936 a 1946, Volpi recorre, sobre la base de documentos ignorados y poco conocidos, el dramatismo de la confrontación/duelo en los límites del colapso psíquico: «iAquel Nietzsche casi me ha destruido!». Nietzsche llega a ser para Heidegger una especie de hilo conductor para pensar hasta el fondo y con radicalidad la negatividad que es inherente al ser. Si en el planteamiento del problema del ser es central Aristóteles, como también «la apropiación asimilativa de la ontología y de la filosofía práctica aristotélicas en los años veinte», con la radical despedida de todas las formas de pensamiento que se fundan en los modos tradicionales del logos y de la ratio, Heidegger «recoge y hace propia la herencia de la finitud y del nihilismo de Nietzsche» ${ }^{6}$.

La inicial presencia saludable del filósofo de la muerte de Dios viene seguida a través del vasto y variado material de la opera omnia: Volpi advierte sobre la importancia de definir el sentido diverso y el estatuto diverso del discurso, cambiado en las diversas formas de comunicación (lecciones, conferencias, ensayos, tratados), distinguiendo «diversos niveles de 'comunicación pública' de su pensamiento, por lo tanto diferentes grados de iniciación a lo largo del camino esotérico a seguir para llegar a su corazón».

El centro de interés es el nihilismo: el enfrentamiento con Nietzsche significa para Heidegger el enfrentamiento con lo moderno, con la técnica, con algo que va mucho más allá de los tradicionales temas especulativos. Nietzsche es el único agarradero que Heidegger encuentra. En ciertos aspectos el trabajo de Volpi sobre el nihilismo ha sido un trabajo sobre la suerte de Nietzsche, sobre las declinaciones del nihilismo a partir de Nietzsche (con testimonios directos e inéditos sobre autores que tienen en Nietzsche y en Heidegger una referencia). El acercamiento de Volpi a Heidegger, del que es ciertamente uno de los más grandes expertos mundiales, era lejano, como él mismo escribe, desde la «admiración supina y a menudo exenta de espíritu crítico, que le ha sido tributada y que ha producido tanta escolástica». No faltan distanciamientos, sobre todo en el último periodo, en relación con la política:

5. La Repubblica, 15 de abril de 2009.

6. F. Volpi, Heidegger e Aristotele, 1984. 
Ha sido el máximo pensador contemporáneo, la encarnación del proto-filósofo, pero al mismo tiempo víctima ilustre de una cerrazón política imperdonable. El pensamiento que aspira a llevar la verdad al corazón del poder, a conjugar la filosofía con la política, ¿no es quizás responsable de las consecuencias que pudo tener su arriesgada alquimia de teoría y praxis? La historia de Heidegger es indicativa de la complejidad del problema. Más que el error del filósofo que ha querido poner las manos en la rueda de la historia universal, quedando trituradas por ella, lo que inquieta es el hecho de que la herida, que su caso ha abierto, la laceración entre filosofía y política, no se ha cicatrizado todavía ${ }^{7}$.

Respecto a las simplificaciones de una reducción del problema exclusivamente al dato biográfico, el caso político de Heidegger se inserta para Volpi en

una borrachera ideológica que involucra y arrolla a pensadores alemanes de las más diversas procedencias: De Simmel a Weber, de Husserl a Scheler; y luego Spengler, Jünger, Thomas Mann, Jaspers. Sobre estos hechos, antes de comenzar procesos contra este o aquel chivo expiatorio, se trataría de indagar y reconsiderar a fondo, en una contextualización histórica más amplia, todo el complejo problema de la relación del mundo de la cultura, de la literatura y del pensamiento alemán con el nacionalsocialismo ${ }^{8}$.

Y, por lo tanto, hay que alejarse de cualquier simplificación: «mezclando el pensamiento de Heidegger y la ideología nacionalsocialista se termina por no comprender ni a Heidegger ni al nacionalsocialismo», escribía en la entrevista de 1988.

Recientemente, la crítica que iba dirigida contra el último Heidegger se movía sobre puntos decisivos como muestra el texto de la introducción a la reciente edición italiana de los Beiträge [Contribuciones], censurada por el hijastro del filósofo, editor responsable de la edición completa. Volpi, quedó muy contrariado y descontento por esta acción, advierte lacónicamente en su «Avvertenza del curatore dell'edizione italiana»: «Debiendo, por disposición de los herederos, suspender toda explicación sobre la génesis, el estilo y el contenido, sólo proporcionamos aquí las indicaciones terminológicas indispensables». Ciertamente, Las contribuciones a la filosofía le parecen a Volpi «el diario de bitácora de un naufragio. Por adentrarse demasiado en el mar del Ser, el pensamiento de Heidegger naufraga. No obstante, como cuando es un gran navío el que se sumerge, el espectáculo que se ofrece a los ojos es sublime». Entre otras cosas se critica la fidelidad de Heidegger al mito de la relación privilegiada germanismo-grecidad del todo hostil a la latinidad, «el mito greco-germánico del originario de reconquistar», «la convicción de que la verdadera filosofía pueda hablar solamente en griego antiguo y alemán (¿̇y el latín?)». Este aspecto de Heidegger contrasta con el Nietzsche «francés», que el trabajo de los aparatos de la edición ColliMontinari y la investigación histórico-filológica han contribuido a definir mejor contra el estereotipo consolidado de pensador esencialmente «germánico». La aproximación de Volpi a Heidegger —y esto vale para las muchas e inéditas exploraciones (con encuentros y clarividentes entrevistas con los vivos) de las

7. F. Volpi y A. Gnoli, «Le conseguenze di Heidegger», en La Repubblica, 20 de octubre de 2008.

8. F. Volpi, «Esaltati di qualità»: L'Indice (febrero de 1992). 
figuras que forman la historia del nihilismo - era una aproximación histórica y filológica dirigida a comprender la crisis profunda de nuestro tiempo, del que los escritores y pensadores son testigos —en la voluntad de orientación, de comprensión sin prejuicios para una posible superación, para poder encontrar vías de salida sin abdicar de la propia tarea.

El Nietzsche de Heidegger representa para Volpi la pars destruens: la práctica del nihilismo cumplido, de aquel que ha proclamado la muerte de Dios:

El verdadero nudo es Nietzsche. En él se concentra simbólicamente el problema de la crisis de la razón con los trastornos que se derivan de ella. El fuego prendido por él arde hoy por todas partes. Él ha afirmado que la razón no es otra cosa que un frágil instrumento orgánico de autoconservación. Dios una hipótesis para reducir la contingencia del caos, la verdad un escorzo perspectivista, una especie de error sin el cual el hombre no podría sobrevivir. Del mismo modo no hay hechos, sino sólo interpretaciones, funcionales para la vida y para su conservación. Sirviéndose de la sutil navaja «genealógica» ha deconstruido los edificios de la razón, acelerando la desvalorización de los valores y el nihilismo. Y su descripción ha tenido un carácter operativo, contribuyendo a producir la crisis que describía.

Volpi hablaba de la «crisis antropológica» que Nietzsche ha explorado y sacado a la luz con una claridad despiadada. Con su afirmación de que el hombre es «el animal todavía no definido» Nietzsche nos ha hecho comprender cómo

el ser humano está expuesto y abierto a dos extremos igualmente arriesgados para su comportamiento, la espantosa naturaleza de sus pulsiones y el carácter ilimitado de su razonar. Nosotros, en la crisis antropológica diagnosticada por Nietzsche, debemos preguntarnos: ¿tenemos una idea de hombre compartida, una antropología adecuada a los problemas que plantean la globalización y la multiculturalidad??

De la crisis antropológica - el hombre como animal no definido, Mangelwesen - se puede salir. No por casualidad esta antropología humana hace referencia a posiciones que están presentes en el Humanismo: la dignitas hominis, la celebración del hombre, se acompaña con la constatación de que el hombre es un animal no definido. Ésta es su libertad. Para Pico el hombre es un «camaleón de la creación», que puede transformarse en un animal o en un ser divino» ${ }^{10}$. Volpi encuentra en Nietzsche la continuidad de una lucha contra la decadencia y el nihilismo a partir de la valoración de la grecidad, en los años de la filología intempestiva, contra la cultura de la época. Por lo tanto, no la posición desesperante del último Heidegger para quien «sólo un dios puede salvarnos»: por el contrario, se trata de tomar el destino en las propias manos, vivir hasta el fondo el nihilismo para tenerlo «detrás de sí, bajo sí, fuera de sí». Con esta cita de Nietzsche Volpi cerraba su volumen sobre Il nichilismo.

Nietzsche aparece entonces como el Spinoza de nuestros días, radical en la renuncia a las ilusiones metafísicas, que lucha contra los residuos de las «sombras de Dios», para el cual la construcción humana no tiene ninguna garantía

9. La Repubblica, 8 de diciembre de 2000.

10. La Repubblica, 18 de agosto de 2005. 
preconstituida, no tiene redes ni protección. Es el diagnóstico sin ilusiones de la crisis de nuestro tiempo, pero también aquel que —a través de un radical «nuevo iluminismo»- trata de superar el nihilismo en la construcción de un sentido, en la voluntad de una plena realización de la vida. Un Nietzsche que se abre a la red compleja y móvil de realizaciones, no al relativismo, hostil en todo caso a las convicciones y la fe que producen fanatismo.

La nueva imagen de Nietzsche madura en Volpi también como un resultado de la edición Colli-Montinari y del trabajo de los aparatos críticos: en primer plano el Nietzsche diagnóstico, el Nietzsche «francés», el «psicólogo» que se enfrenta a la décadence y al nihilismo. De ahí la valoración de un autor como Paul Bourget en el centro del ensayo de 1995 «Sulla fortuna del concetto di 'décadence' nella cultura tedesca: Nietzsche e le sue fonti francesi». Para Nietzsche Paul Bourget atraviesa y diagnostica como «psicólogo» — con sus ensayos y sus novelas— los múltiples signos del nihilismo y de la decadencia en las actitudes culturales más significativas de la época. La falta de un credo colectivo, el fin de la viejas religiones, el nihilismo de la ciencia, el diletantismo, el cosmopolitismo, la difusión del budismo, la hybris analítica llevada hasta la vivisección psicológica, etc., son fenómenos ligados al desgaste fisiológico, a una impotencia general hacia la vida. Bourget ha tenido como objeto «la extraña vegetación que constituye el 'yo' de un hombre civilizado», los «monstruos» y los héroes de la decadencia a los que se ha sentido cercano, con quienes ha compartido el aura de excepcionalidad y diferencia. Bourget en particular ha señalado a Nietzsche un camino para profundizar el camino.

También en el Nietzsche perfecto nihilista de Europa hay para Volpi algunos aspectos que valorar: el nihilismo es el fin de perspectivas privilegiadas ya dadas y la libertad de las convicciones que son prisiones. Se «han corrompido las verdades y debilitado las religiones», «ha disuelto también los dogmatismo y ha hecho caer las ideologías, enseñándonos así a mantener aquella razonable prudencia del pensamiento que nos permite navegar visiblemente entre los escollos del mar de la precariedad, en la travesía del devenir» ${ }^{11}$. La actitud, la práctica de vida que deriva de ello es la actitud constante con la filosofía del «espíritu libre», con el «nomadismo intelectual» de Nietzsche. Significativamente, Volpi escribe en la introducción (con Gnoli) a las cartas del viaje a Italia de Freud ${ }^{12}$ :

Pero, ¿de dónde nace la pasión por los viajes? ¿Qué es —nos preguntamos— esa extraña y periódica exigencia de desplazarse? Quizás el viaje es un recurso de la vida. Un movimiento connatural a la necesidad de evitar algo y a la posibilidad de conquistar algo nuevo y diverso. Una dinámica que es inherente a la existencia, que dimana de la exigencia de ponerse una meta, un sentido hacia el que orientar aquel movimiento inagotable que es la vida, y que sólo la felicidad o la muerte apagan. [...] Es quien está bien sólo «en otro lugar». Quien está siempre a la búsqueda de otra cosa. Siempre de viaje. Quien peregrina también cuando no se mueve de casa. $\mathrm{Al}$ contrario de aquellos que están en casa también cuando viajan.

El «nomadismo intelectual»se abre a la pars construens del filosofar de Nietzsche, que asume en sí hasta el fondo la decadencia y el nihilismo para

11. F. Volpi, Il nichilismo, op. cit.

12. S. Freud, Il nostro cuore volge al Sud. Lettere di viaggio. Soprattutto dall'Italia (18951923), Milano: Bompiani, 2003. 
encontrar una vía de salida. En esta dirección Volpi valora a otro autor francés en la trayectoria de Nietzsche: Jean-Marie Guyau, que, haciendo referencia a la moral antigua, en su escrito Esquisse d'une morale sans obligation ni sanction de 1885, afirma una ética de la vida contra la ética kantiana del puro deber. La vida, en el momento en que toma conciencia de sí, tiende a acrecentar la propia fuerza, a intensificarse. La vida es una especie de "gravitación sobre sí misma»: tiene necesidad de potenciarse, de acumular un superplus de fuerza para conservarse. La vida tiene la tendencia esencial a expandirse, a salir de sí misma, a darse. Esta expansión es fecundidad; por el contrario, el egoísmo aparece como una autolimitación de la vida.

Como había escrito Volpi también en aquel último artículo suyo en respuesta a los anatemas del pontífice, la intención de Nietzsche es la de «superar la esterilidad de la prohibición simple, de la abnegación y de la renuncia, que mortifican la vida. Nietzsche quiere que la vida se realice en todas sus potencialidades. Y aconseja por eso una actitud «creativa» que dé a la vida toda su plenitud, análoga a la actitud del artista que imprime en su obra una forma bella. En tal sentido la nueva moral es una especie de «estética de la existencia» cuyo imperativo recomienda: «iLlega a ser lo que se es! Y aunque la vida no sea bella, está de nuestra parte hacerla bella». Una filosofía, por lo tanto, que hace referencia a la ética de los antiguos, a la sabiduría como transformación de la vida encontrándose en esta valoración con Schopenhauer, el educador de sus años jóvenes. La sentencia de su vida, sobre la que Nietzsche ha vuelto más veces, es: «iLlega a ser lo que eres!» ${ }^{13}$, a cuyo sentido Volpi había dedicado recientemente un análisis completo. La cita tiene para Nietzsche valor emblemático. Aparece por primera vez como lema de su ensayo juvenil De Laertii Diogenis fontibus y la vuelve a retomar como subtítulo de Ecce homo ("Cómo se llega a ser lo que se es»), además de encontrarse en otros puntos centrales de su trayectoria sacados a la luz y comentados por Volpi, cuyo análisis remite también a la repetida exhortación a Lou von Salomé ${ }^{14}$ :

En fin, mi querida Lou, el antiguo, profundo y cordial ruego: illegue a ser lo que es! Al principio nos cuesta trabajo emanciparnos de nuestras cadenas, iy al final también tenemos que emanciparnos de esta emancipación! Cada uno de nosotros, aunque de maneras distintas, tiene que trabajar esta enfermedad de las cadenas, también después de haberlas roto.

Las cadenas son «los errores graves y a la vez sensatos de las ideas morales, religiosas y metafísicas impuestas por el hombre para separarlo de su feliz libertad animal».

Volpi había abordado el tema de una ética no imperativa y el sentido de la máxima de Nietzsche en su conferencia de Granada de octubre de 2008 dedicada a "'Werde, der Du bist!' El imperativo de una estética de la existencia según Nietzsche». La conferencia, no publicada, terminaba con una cita de Séneca (en la carta 32 a Lucilio) y otra de Epicteto ${ }^{15}$. «Consummare vitam ante mortem». Es necesa-

13. Píndaro, Píticas, II, v. 72: «Sé aquel que aprendiste a ser».

14. A L. von Salomé, finales de agosto de 1882, en CO IV, carta 293.

15. Epicteto, Diatribas, III, 5, 5 . 
rio llevar a cabo la propia vida antes de la muerte, alcanzar la perfecta saciedad de sí mismos. La máxima de Seneca era comentada con las palabras de Epicteto:

¿No sabes que la enfermedad y la muerte deben cogernos en medio de alguna ocupación? Cogen al campesino mientras está arando, o al marinero durante la navegación. ¿Y sin embargo, dado que te cogerá con una de ellas, en qué ocupación quisieras ser sorprendido? Si por tanto puedes serlo mientras estás participando en una actividad mejor de aquella a la que te estás dedicando actualmente, practícala.

Nietzsche, practicando la sabiduría de los antiguos, se volvía al Schopenhauer de los Parerga. Volpi acompañaba su lectura de Nietzsche con una reflexión sobre la escritura aforística que corresponde al carácter fragmentario y transitorio de la vida como ya lo afirmaba Schopenhauer en la máxima n. ${ }^{\circ} 21$ de la Eudemonología:

Puesto que los acontecimientos de la vida que nos esperan aparecen y se desenvuelven de manera inconexa, fragmentarios, sin relación recíproca, en el contraste más estridente, sin nada en común excepto el hecho de que son asuntos nuestros, debemos organizar nuestros pensamientos y nuestras preocupaciones respecto a ellos de manera igualmente fragmentaria, a fin de que podamos corresponderles; debemos saber abstraer, ponderando, cultivando, saboreando, soportando cualquier cosa a su tiempo, despreocupándonos de todo lo demás; debemos poseer, por decirlo así, cajones de nuestros pensamientos, y que, cuando abramos uno de ellos, cerremos todos los demás...

A Volpi le gustaba citar a este propósito una carta de Gottfried Benn a Oelze (27 de diciembre de 1949) que trataba de explicar la coherente fragmentariedad de la obra Nietzscheana: "Ahora comprendo por qué Nietzsche escribía con aforismos. Quien no ve ya conexiones, ni ninguna huella de un sistema, puede únicamente proceder por episodios». Pero últimamente Volpi respondía a Benn tomando una expresión usada por Gómez Ávila (su descubrimiento colombiano del que extraía más temas sugestivos para aproximarse a Nietzsche) a propósito de sus «escolios». «De manera distinta que Benn, podemos pensar que sus aforismos no son fragmentos inconexos, sino toques cromáticos de una composición puntillista que nos hace ver el conjunto». Una constelación de sentido que exige la participación activa del lector.

Tras las huellas de Nietzsche se valora también la función terapéutica de la filosofía y de los aforismos en la práctica cotidiana de la escritura: «No sé si experiencias de vida bajo forma de sentencias serán útiles a los demás, pero lo cierto es que para quien las escribe son algo beneficioso: son un medio de aliviar la vida ${ }^{16}$. En la recuperación de una ética de la realización y construcción de sí mismo, hostil a la ética kantiana que excluye la eudaimonía, la realización y el potenciamiento de la vida, una ética normativa hecha de imperativos y de prohibiciones, el Nietzsche de Volpi (que sigue a Guyau) se encuentra con el Schopenhauer de Volpi no insertado en el recorrido del nihilismo. Con su trabajo histórico y filológico de editor y de intérprete, Volpi ha contribuido de manera decisiva a recuperar a Schopenhauer para la gran filosofía en su relación con

16. FP II, primavera-verano $1877,22[15]$. 
las fuentes científicas y culturales del tiempo, pero ha valorado también y sobre todo de ellas la práctica lección de la sabiduría de la vida, el difícil arte, sobre fondo pesimista, de saber navegar entre los escollos para evitar el naufragio. También en este caso: historia y filología en la base de un trabajo del legado de Schopenhauer que conserva numerosos e importantes textos inéditos.

Análogamente a cuanto hicieron Colli y Montinari por Nietzsche, Volpi emprendió una nueva edición de los póstumos de Schopenhauer que, teniendo como base la edición de Hübscher, la completó incluyendo lo que éste no había considerado, por ejemplo, los llamados Orientalia y los cursos universitarios berlineses. La relectura de los manuscritos ha enriquecido de inéditos la nueva edición de los Scritti postumi, pero también la serie de los afortunados libritos schopenhauerianos nace a partir de los materiales póstumos, como la Dialéctica erística (1991), el Tratado sobre el honor (1887), la Eudemonología (1998). En colaboración con su amigo Giovanni Gurisatti, Volpi ha procedido en el trabajo interpretativo a demostrar cómo sobre la base de los póstumos se puede colmar la aparente fractura entre El mundo como voluntad y representación y los Parerga y paralipomena, entre la metafísica del pesimismo y la sabiduría de la vida, entre la parte especulativa y la práctica del sistema schopenhaueriano. En la amplia introducción a la nueva edición de los Aforismos sobre la sabiduría de la vida (2007), con un aparato de notas muy adecuado, que faltaba hasta ahora, Volpi presenta a Schopenhauer como el pensador de la eudemonologia y del cuidado de sí. Volpi estaba a punto de completar y de publicar la primera edición integral alemana del manuscrito de los Senilia (1852-1860), que la misma edición Hübscher del Nachlaß presenta con muchas lagunas y con notas en el aparato crítico que son insuficientes. Precisamente, en el ensayo introductorio del último pequeño volumen de la afortunada serie schopenhaueriana dedicado por una trágica paradoja a El arte de envejecer (2006), Volpi da la definición y el sentido del filosofar, de la pasión del filosofar con la plena conciencia de que la filosofía «no resuelve los problemas. Enseña, si acaso, a plantearlos. Es decir, a inventar razones para dudar de lo evidente».

La filosofía - esta singular modificación de la vida que hace posible su comprensión- no debe poner a distancia la vida misma para observarla en una consideración teorética neutral y «reificarla», o sea, reducirla a una cosa entre las cosas, a objeto entre los objetos. La filosofía [...] es también comprensión práctica de la vida que le da forma y la orienta. Es sabiduría y cuidado de sí.

Esta actitud no significa narcisismo sino enriquecimiento y sensibilidad crítica hacia la miseria de la época. Entendida como cuidado de sí, la filosofía implica un conjunto de meditaciones, de reflexiones y ejercicios «espirituales» que dan cuerpo a una «estética de la existencia» o, más bien, a una «filosofía práctica» capaz de plasmar la existencia como se plasma una obra de arte, imprimiéndole una forma bella y conseguida de la que emana «serenidad». En este sentido, los autores de Volpi son Schopenhauer y Nietzsche. En ellos reconoce la práctica de un ethos personal: para Schopenhauer se trata, sobre el fondo metafísico de la Voluntad una e inmodificable, de elecciones de vida dirigidas a evitar el sufrimiento, a reducirlo al mínimo, a navegar entre los escollos con prudencia para evitar el naufragio, mientras que para Nietzsche el ethos personal corresponde 
al potenciamiento máximo y a la plena realización de sí.

Contra el dormitar en un «ociosidad alejandrina» de la filosofía académica o en una reflexión reducida a «una noble anábasis, a una retirada estratégica de las grandes cuestiones para refugiarse en problemas pormenorizados», Volpi quiere una práctica filosófica que reivindique su competencia en la búsqueda del sentido de la vida y de su orientación ${ }^{17}$. Franco Volpi: una gran pasión del conocimiento, una gran pasión filosófica que era sobre todo gran pasión por la vida. Cuanto antes se tratará de estudiar a fondo y analizar las aportaciones originales de su trabajo, para seguir sus indicaciones, para ver en qué medida y en qué dirección es posible continuar la obra interrumpida en su plena y madura actividad.

He querido recordar aquí algunos momentos que nos han unido profundamente y han marcado una trayectoria común: en particular recuerdo una gratificante estancia en México en mayo de 2008, donde nos dedicamos a dar conferencias y clases. Recuerdo nuestra plena consonancia unida a su fuerte vitalidad y la manera en que reíamos felizmente juntos.

\section{HEIDEGGER Y SU SOMBRA \\ Entrevista a Franco Volpi sobre el caso Heidegger \\ De Giovanni Gurisatti $1 \frac{18}{}$}

Portofranco: Profesor Volpi, la publicación de una colección de escritos de un gran pensador es siempre un acontecimiento que no impacta solamente en el círculo estrecho de los especialistas, sino que fascina y abarca también a un sector más amplio de lectores y de gente interesada. ¿Cuál es la importancia de Hitos (Wegmarken) y qué novedades puede aportar esta recopilación para la recepción, especializada o no, del pensamiento de Heidegger?

F. Volpi: La importancia de Hitos está ante todo en el hecho de que allí se encuentran reunidos los ensayos más significativos del «segundo» Heidegger, aquellos que indican las etapas fundamentales de su camino especulativo desde Ser y tiempo en adelante. El título de la recopilación (en alemán Wegmarken) quiere significar que estos ensayos representan indicaciones, signos, que trazan e indican la vía abierta y seguida por Heidegger, como Caminos del bosque (Holzwege) o De camino al habla (Unterwegs zur Sprache). Esto indica una vez más que el pensamiento de Heidegger, cuanto más madura es la perspectiva que le es propia, tanto más asume el carácter de «estar en camino», es decir, el carácter de un pensamiento que está en camino hacia una meta, a la que mira de manera indefensa, pero sin pretensiones de certeza y de que consiga esa meta totalmente: que es luego el modo típicamente heideggeriano de concebir el pensamiento en cuanto pensamiento de la finitud. Por eso, como lema epigráfico de las propias Obras completas, que se están publicando en Alemania y que comprenderán

17. La Repubblica, 17 de septiembre de 2005

18. Publicado en Porto Franco 2 (mayo de 1988), 2-7. 
cerca de 100 volúmenes, Heidegger ha querido escribir: «Caminos, no obras» («Wege, nicht Werke»), o también, «Senderos, no obras». En cuanto a los textos que se incluyen allí, se trata de escritos de una extraordinaria profundidad e importancia. Basta con pensar, por ejemplo, en la conferencia «¿¿Qué es metafísica?», pronunciada por Heidegger en 1929 en Friburgo (donde había sido llamado para suceder a Husserl); allí Heidegger se pregunta sobre qué es la metafísica, en su esencia más profunda, y al hacer esto pone radicalmente en cuestión el modo en que ella misma se ha comprendido, desarrollando las célebres reflexiones sobre la «angustia», como estado de ánimo fundamental en el cual la Nada y el Ser, en cuanto radicalmente distinto del ente, se nos manifiestan, reflexiones que suscitarán la no menos célebre reacción polémica de Carnap. O La doctrina platónica de la verdad, texto que se remonta a su primera composición de comienzos de los años treinta, pero que no fue publicado hasta 1942 (en un anuario dirigido por Ernesto Grassi), y con el cual Heidegger hizo pública por primera vez su interpretación de la «decisión metafísica» que marca la historia occidental —y con la cual se inaugura la preeminencia de la «subjetividad» sobre el ente, la prioridad del artefacto y del producto sobre lo que es la Naturaleza-, y tal giro, como es conocido, es por él individuado a través de una célebre interpretación del mito platónico de la caverna. Sigue siendo esencial la Carta sobre el humanismo, en la que Heidegger, tomando posición contra los diferentes «ismos» de los que se alimenta la cultura contemporánea, contra la ideología de los valores y contra las distintas esperanzas neofundacionales hoy difusas, ofrece un lúcido análisis de las patologías de la época presente, buscando individuar sus razones más profundas. Importantísima, por citar un escrito último, es finalmente La cuestión del ser, una carta de respuesta a Ernst Jünger, en la que Heidegger afronta la cuestión del nihilismo y de su posible superación, buscando de nuevo llegar a las raíces metafísicas del malestar de nuestro tiempo.

A la luz de estos y de los otros textos comprendidos en Hitos, se puede constatar en directo que la importancia de esta obra va mucho más allá del significado interno que tienen los textos allí recogidos para la comprensión del pensamiento heideggeriano. A pesar de su carácter aparentemente abstracto impresión que es suscitada por la extrema concentración de Heidegger sobre el problema para él fundamental del Ser-, estos escritos suyos están impregnados de una atención vigilante y preocupada por los problemas fundamentales de la época contemporánea. Son los problemas de un mundo de los que la técnica se ha convertido en el horizonte omnicomprensivo e infranqueable, más aún, en su esencia misma, y precisamente ocupando el puesto que han dejado vacío los dioses huidos y que todavía no ha sido llenado por el dios nuevo que ha de venir. Pero, ¿̇uáles son estos problemas? Son el fin de lo Absoluto sobre la tierra y el venir a menos de la conciencia religiosa, el eclipse de lo Sagrado y la disgregación de los valores tradicionales, la consunción de todo sentido y la "pérdida del centro", la desconfianza en el poder de una religión solamente instrumental, la vanidad de las compensaciones ofrecidas por la vuelta a formas de pensamiento ingenuo y sentimental.

Todas éstas son cuestiones que Heidegger, con una radicalidad que después de Hegel ningún otro había osado, ha sabido pensar en una profunda conexión con la historia de Occidente y con su inicio esencial, el representado por la filosofía griega. Por eso, leyendo a Heidegger, una vez que se ha superado la difi- 
cultad de su lenguaje difícil y demasiado conceptual, se comprende rápidamente que sus escritos atañen a un destino que nos afecta a todos.

Portofranco: Recientemente la discusión en torno a Heidegger, incluida la que siguió a las afirmaciones contenidas en el controvertido libro de Víctor Farias $^{19}$, se ha reactivado a partir de la debatida polémica relativa a su temporal adhesión al nazismo. Frente a la espinosa cuestión, a menudo heideggerianos y «heideggeriólogos» se han limitado a encogerse de hombros. ¿Está de acuerdo con esta última postura? ¿Qué piensa de las afirmaciones contenidas en el libro de Farias a propósito de Heidegger y el nacionalsocialismo?

F. Volpi: Periódicamente alguno descubre que Heidegger ha sido un nazi. Farias es uno de ellos. Su libro ha tenido la suerte de estar apoyado por una masiva campaña publicitaria, pero al mismo tiempo su desgracia ha sido que en más de un caso $^{20}$ los periodistas que la mantenían demostraban haberse enterado por primera vez por Farias de la adhesión de Heidegger al nacionalsocialismo. Frente a una tal ignorancia encogerse de hombros es naturalmente la actitud más inmediata, y quizás no es sin embargo lo más sabio. Pero es necesario decir que también por parte de algunos heideggerianos «ortodoxos», especialmente alemanes y franceses, ha habido actitudes igualmente ciegas. Ha habido alguno, por ejemplo, que ha pretendido demostrar que después de su temporal adhesión, Heidegger habría pensado y vivido en medio de una radical resistencia al nacionalsocialismo; y han sido citados como prueba actos de hostilidad que él habría debido padecer por ello, como algunas severas recensiones de sus escritos en las revistas oficiales del partido, dificultades de distinto tipo para publicar sus escritos y difundirlos; además, hacia el final de la guerra, por su actitud hostil frente al régimen, al filósofo ya anciano no le habrían perdonado ni siquiera los trabajos forzados en el frente del Rin. Lo que es excesivo, si no claramente falso, y le hace a Heidegger un mal servicio.

Diré, entonces, que el libro de Farias tiene a pesar de todo un mérito, el de haber quemado el terreno bajo los pies de este género de hagiografías. Dicho esto, sin embargo, añado rápidamente que se trata del único "efecto positivo» del libro, mientras que por lo demás no se le puede prestar mucha atención. Digo «efecto», y no «mérito», porque el resultado es producto más de la ineptitud ajena que del coraje de Farias. A pesar de todo un instrumental de erudición llamativa -a menudo faltan sin embargo referencias precisas, en otro lugar el texto y la traducción están plagados de burdos errores, se ignoran fuentes esenciales, mientras que otras absolutamente marginales vienen exprimidas hasta lo inverosímil-, el libro de Farias es creíble sólo allí donde recoge lo que ya se sabía (sobre todo gracias a una antigua antología de Guido Schneeberger y, más recientemente, por mérito de los estudios del historiador Hugo Ott); en las pocas novedades que descubre, resulta por el contrario fundamentalmente sospechoso. En todo caso, a pesar del gran número de archivos visitados por Farias (incluidos

19. V. Farias, Heidegger y el nazismo, trad. del español y del alemán por M. Bennaroch y J. B. Crasset, prefacio de Chr. Jambet, Verdier, Lagrasse, 1987; la traducción italiana está anunciada por la editorial Bollati Boringhieri. ¿trad. española?

20. Cf. el artículo aparecido en La Repubblica, 19 de octubre de 1987. 
los de la República Democrática Alemana), se puede decir: lo que el libro cuenta de relevante no es nuevo, y lo que dice de nuevo no es relevante.

Si se me permite entrar un poco más en detalle, quisiera denunciar también algunos aspectos del libro absolutamente inadmisibles, tanto más en una investigación de «comprobada seriedad científica»: así viene presentado el libro por el editor italiano que lo ha hecho traducir. (Me pregunto: ¿comprobada por quién? Por el contrario, resulta que precisamente en Italia, pero no sólo entre nosotros, más allá del problema que el libro involuntariamente plantea, el de la conexión entre el pensamiento y la biografía de un pensador o, si se quiere, el de la responsabilidad moral y política de un filósofo, las tesis de Farias han sido duramente criticadas.) Arriesgada y traída por los pelos aparece ante todo la hipótesis de fondo del libro, que representa un poco el lecho de Procusto sobre el que se echan y se tienden los hechos conocidos y menos conocidos de la biografía de Heidegger: quiero decir, la fantasiosa idea, fervorosamente sostenida por Farias, según la cual Heidegger habría sido un nazi desde su nacimiento. Esto estaría apoyado por un breve discurso del todo ocasional que pronunciara de estudiante sobre el monje agustino Abraham a Sancta Clara, un paisano suyo que vivió en el siglo xviI y en cuyos escritos se insinúa un antisemitismo radical (actitud que en aquel periodo estaba bastante difundida, algo que Farias parece ignorar; en todo caso no es ciertamente el antisemitismo la razón por la cual el joven Heidegger se interesó por él, diga lo que diga Farias). Y más allá de los bien conocidos acontecimientos de 1933-1934, Heidegger habría seguido siendo nazi hasta el final, como mostraría el hecho de que a los 75 años, de nuevo en un discurso conmemorativo en su pueblo natal de Messkirch, vuelva a hablar de Abraham a Sancta Clara. Pregunto: ¿́por qué Abraham de Sancta Clara sería la prueba de la inclinación de Heidegger al antisemitismo y al nacionalsocialismo, y no por ejemplo Lutero, con el cual Heidegger confronta mucho más a fondo y en el cual también se encuentra un antisemitismo? Y ¿́por qué no Nicolás de Cusa o uno de tantos otros pensadores alemanes de aquella época que se enfrenta a los judíos?

Dada esta premisa, está claro que en el libro «de acertada seriedad científica» de Farias, todo y lo contrario de todo contribuye inexorablemente a predestinar a Heidegger al nazismo. De ahí se sacan grotescas ilaciones que han sido ya destacadas por muchos, por ejemplo, entre aquellos que lo han hecho con mayor sutileza, como Pierre Aubenque ${ }^{21}$ y Vittorio Mathieu ${ }^{22}$. Me limito a recordarlas y a denunciar algunas.

Es curioso, por ejemplo, que para predestinar a Heidegger al nazismo concurran en la reconstrucción biográfica de Farias más o menos todas las circunstancias de su formación, también aquellas más antitéticas: el catolicismo del ambiente familiar, porque - nos explica Farias - se trataba de un catolicismo reaccionario y antisemita; el bismarckismo de algunos de sus profesores; pero también el anticlericalismo de algunos otros que - explica de nuevo Farias- se habría directamente integrado a continuación en el fascismo. Pero, ¿̇y el hecho de que Heidegger se case con una protestante o que abandone la fe católica en torno a 1918? Aquí se comporta Heidegger, sigue explicándonos Farias, como un oportunista (basta con leer la carta del 9-1-1919 de Heidegger a Engelbert

21. En un artículo aparecido en el n. ${ }^{\circ} 9$ de la revista Le débat, pp. 113-123.

22. En Il Giornale, 24 de octubre de 1987. 
Krebs, que hasta entonces había sido su amigo y padre espiritual, para intuir rápidamente que es ciertamente todo lo contrario, es decir, que Heidegger no rompió con el catolicismo por oportunismo, sino que lo hizo en contra de sus propios intereses prácticos, por razones filosóficas). Incluso el éxito que Heidegger tuvo luego con los estudiantes llega a ser para Farias una prueba de nazismo. He aquí lo que escribe Farias en la p. 69: «Es en este periodo cuando Heidegger comenzó a mantener relaciones estrechas con el mundo estudiantil, lo cual es decisivo para comprender su ulterior empeño en favor del nacionalsocialismo». En resumen, ijustamente todo y lo contrario de todo! Pero no ha terminado. Retornando a la increíble interpretación que Farias hace del interés ocasional del último Heidegger por Abraham a Sancta Clara, se señala que aquí se puede leer entre líneas de la breve conferencia pronunciada por Heidegger sobre la figura del monje agustino una preocupante «trilogía»: «Abraham a Sancta Clara/Sachsenhausen/Auschwitz» (p. 293). Pero veamos cómo Farias llega a tal «descubrimiento». En un momento de su discurso Heidegger cita un pasaje de Abraham a Sancta Clara en el que se dice que «nuestra paz es tan lejana de la guerra como Sachsenhausen de Fráncfort». Cualquiera en Alemania sabe bien que se trata de un modo de decir que juega con la cercanía de Sachsenhausen de Fráncfort; cualquiera que haya frecuentado un buen instituto - precisamente es a los estudiantes de bachillerato a los que se dirige Heidegger- sabe perfectamente que el modo de decir es empleado también por Goethe en su Götz von Berlichingen. Naturalmente Farias se las sabe todas: en Sachsenhaus había un campo de concentración (en realidad el campo de concentración estaba situado en una localidad homónima que no tiene nada que ver con el suburbio de Fráncfort aquí en cuestión), y el nombre de Fráncfort no le recuerda a Farias, por ejemplo, a Goethe, Schopenhauer y la teoría crítica de la sociedad, sino la circunstancia de que en Fráncfort tuvo su sede el tribunal para los crímenes de guerra. Y ésta es la delirante trilogía de Farias: «Abraham a Sancta Calra/Sachsenhausen/Auschwitz».

En cuanto al periodo del compromiso de Heidegger como rector de la Universidad de Friburgo (abril de 1933-abril de 1934), es conocida la versión de los hechos dada por Heidegger en la entrevista «Sólo un dios nos puede salvar»: él habría aceptado la carga de rector contra su voluntad, a consecuencia de la insistencia de los colegas preocupados por las injerencias del partido en la vida académica y universitaria, y una vez asumido el rectorado habría tratado de mantener y de defender la autonomía de la universidad, como lo confirmaría claramente, por lo demás, el famoso discurso de 1933 sobre «La autoafirmación de la universidad alemana». En este cargo habría tenido continuas tensiones con el partido, tanto que terminó por presentar la dimisión antes de tiempo, después de menos de un año de su nombramiento. Sabemos también, naturalmente, que en su versión Heidegger no lo dice todo. El historiador Hugo Ott, en una serie de artículos poco conocidos porque fueron publicados en lengua alemana y en revistas difíciles de localizar, ha propuesto la hipótesis, sobre la base de una serie de documentos recogidos en varios archivos, de que en realidad los enfrentamientos con el partido comenzaron no tanto por las razones indicadas por Heidegger, sino por el hecho de que él habría aspirado a convertirse en el líder del movimiento y a organizar la vida cultural y universitaria sobre el plano nacional, pero que en el seno del partido nacionalsocialista tales aspiraciones no fueron tomadas en serio, terminando incluso por estar abiertamente en contra 
de ideólogos tales como Alfred Rosenberg y Ernst Krieck. Farias, que explota a manos llenas las investigaciones de Ott, añade una fantasiosa hipótesis personal (que el muy serio H. Ott ha definido como «aventurada» o, como mínimo, «problemática»), para la cual sin embargo no tiene pruebas al escribir: Heidegger se habría adherido a las facciones extremistas del partido guiadas por Ernst Röhm, y se habría retirado del cargo de rector y de su compromiso político después de que tal facción resultase vencida y fuese eliminada (en la «noche de los cuchillos largos» del 30 de junio de 1934). La hipótesis parece fantasiosa, ante todo porque las fechas no coinciden, pero además, porque si se va a ver lo que escribían contra Heidegger los ideólogos nazis vencedores, en particular A. Rosenberg y E. Krieck, y precisamente ya desde febrero de 1934, por lo tanto bastante antes de la eliminación de Röhm, no se encuentra ninguna alusión a la presunta adhesión de Heidegger a la línea «de izquierdas» sostenida por este último.

En cuanto a los acontecimientos que siguieron a 1934, tampoco aquí hay nada nuevo que sea verdaderamente importante. Los únicos descubrimientos de Farias son el hecho de que Heidegger habría continuado inscrito en el partido y que habría pagado hasta el final su cuota y que, contrariamente a cuanto él afirma en la ya citada entrevista a Der Spiegel, habría seguido tranquilamente publicando, como por ejemplo el célebre ensayo sobre La doctrina platónica de la verdad, que, por lo que asegura Farias, apareció, a pesar de la oposición firme de A. Rosenberg, en el anuario dirigido por Ernesto Grassi Geistige Überlieferung nada menos que gracias a la intervención del embajador italiano en Berlín Dino Odoardo Alfieri, a la del entonces ministro fascista Giussepe Bottai, y hasta la del mismísimo Mussolini, los cuales habrían presionado a Goebbels. (Incluso aquí, otra vez: el hecho de que fuesen necesarias todas estas presiones para publicar un texto de Heidegger significa que no es por lo tanto verdad que él pudiese publicar «tranquilamente».)

Pero más allá de todo esto, el problema es otro. Y es que el libro de Farias está movido en realidad por el intento de desmontar el pensamiento de Heidegger a través de la biografía del filósofo. Se trata por lo tanto de una de aquellas típicas tentativas de demolición «indirecta»o «trasversal» a la que a menudo los grandes pensadores se ven sometidos (piénsese en el caso de Giovanni Gentile, que sin embargo se comprometió bastante más y durante mucho más tiempo que Heidegger). Pero no es la primera vez que esto sucede. Hace años, desde un punto de vista «sociológico", lo había hecho Pierre Bourdieu, en un ensayo titulado La ontología política de Martin Heidegger ${ }^{23}$, al que Gadamer hizo una crítica demoledora en una durísima recensión. Incluso antes y, a decir verdad, en otro nivel distinto, se había aventurado en la empresa también Adorno en La jerga de la autenticidad (1964) y antes todavía Lukács en La destrucción de la razón (1954), donde, sin embargo, Heidegger estaba todavía en buena compañía, quiero decir junto a Dilthey, Bergson, Simmel, Husserl, Scheler, Jaspers y todos los otros «irracionalistas». Recientemente lo ha probado también Jürgen Habermas en El discurso de la modernidad. Es cierto que Farias no merece estas comparaciones, desde el momento en que el conocimiento del pensamiento de Heidegger que él demuestra, y con el cual pretende bloquear al filósofo, es cuan-

23. Aparecido en 1975 en Actes de la recherche en sciences sociales, y ahora publicado como pequeño volumen en Minuit, Paris, 1988. 
do menos rudimentario. Derrida justamente ha observado que, leyendo su libro, uno se pregunta «si ha leído a Heidegger más de una hora». Pero repito: a pesar de Farias, y sin ánimo de ofender a Adorno y Lukács, la verdad es que Heidegger - se lo tenga sujeto o no al nacionalsocialismo- permanece como el más grande pensador de nuestro siglo.

Portofranco: Si, por un lado, parece evidente que las elecciones políticas del hombre Heidegger no pueden comprometer la sustancia de su pensamiento, persiste sin embargo el problema de comprender cuál era la relación entre su pensamiento y la ideología nacionalsocialista.

F. Volpi: Lo que parece claro es que entre las dos cosas no hay ninguna relación. Ser y tiempo es en realidad una obra apolítica y la adhesión de Heidegger al nacionalsocialismo no fue un acto filosófico.

A este respecto es interesante lo que señala Derrida. Con la agudeza que le caracteriza, recientemente ha mostrado que precisamente la utilización en sentido político que Heidegger hace del concepto de «espíritu» (Geist) en el discurso pronunciado con ocasión de la toma de posesión del rectorado, haciendo referencia con tal concepto directamente al pueblo alemán y a su misión histórica, si acaso va contra la radical crítica que de tal concepto, como de los otros conceptos de la metafísica, el mismo Heidegger había hecho en Ser y tiempo ${ }^{24}$.

Por eso, creo que los intentos de demostrar que existe una cierta conexión entre pensamiento heideggeriano e ideología nacionalsocialista están abocados al fracaso. Ha fracasado el intento de Lukács, que además ha inducido por reacción, especialmente en Italia, un convencimiento exactamente opuesto a aquel del que trataba de persuadir. Ha fracasado el intento de Adorno. Más aún, uno de los alumnos marburgueses de Heidegger, que después ha estado cerca de Adorno, Herman Mörsch, ha mostrado las impresionantes afinidades que tienen en común la implantación especulativa y la problemática de Adorno con el pensamiento de Heidegger. Y ha fracasado en el fondo también aquel, muy agudo, hecho por Karl Löwith en sus Ensayos sobre Heidegger de 1954 y en las consideraciones contenidas en su autobiografía, que se extiende hasta 1939, pero que ha sido publicada hace poco ${ }^{25}$. Esta última contiene, por otra parte, muchas indicaciones que habrían podido interesar a Farias, pero que Farias no conoce. Löwith ha tratado de demostrar que el pensamiento de Heidegger está invadido por una actitud fundamentalmente antidemocrática y - como costa especialmente de Ser y tiempo- por un radical decisionismo, por un pathos de la «decisión por la decisión», en el que no se dan criterios orientativos para decidir sobre los contenidos de la decisión misma por cuanto sugestivo y fascinante que pudiese parecer a las jóvenes generaciones alemanas en plena crisis de los años veinte, eso mostró toda su peligrosidad apenas fue llenado de contenidos como «misión histórica» o la «voluntad esencial» del pueblo alemán o la «renovación» o el «nuevo comienzo» del «espíritu alemán». Pero repito: este intento tampoco va muy lejos, y querer vincular el pensamiento de Heidegger con estas

24. J. Derrida, De l'esprit. Heidegger et la question, Paris: Galilée, 1987. Hay trad. española.

25. K. Löwith, Mein Leben in Deutschland vor und nach 1933 [Mi vida en Alemania antes y después de 1933], Stuttgart: Metzler, 1986. Hay trad. española. 
acusaciones sería como querer clavar un flan en una pared. Además: mezclando el pensamiento de Heidegger y la ideología nacionalsocialista se termina por no comprender ni a Heidegger ni el nacionalsocialismo, con todas sus componentes específicas, como por ejemplo aquella retórica «de la sangre y el suelo» que no fue ciertamente inventada por el nacionalsocialismo, sino por los románticos políticos, y que los nazis, si acaso, explotaron hábilmente, al igual que explotaron muchos otros componentes de la cultura alemana.

Por lo demás, los mismos ideólogos nacionalsocialistas habían comprendido que entre Heidegger y su Weltanschauung no había concesiones posibles. Ya en 1934, en la revista Volk im Werden, dirigida por él, el ideólogo nacionalsocialista E. Krieck escribía:

El tono fundamental de la visión del mundo sostenido en las enseñanzas de Heidegger está determinado por conceptos como cuidado y angustia, y ambos miran a la nada. El sentido de esta filosofía es un ateísmo explícito y un nihilismo metafísico, el mismo que sostienen especialmente autores judíos, por consiguiente un fermento de descomposición y de disolución del propio alemán. En Ser y tiempo Heidegger filosofa conscientemente e intencionadamente en torno a la "cotidianeidad"; no se encuentra nada allí, por el contrario, con respecto a pueblo y Estado, a raza $\mathrm{y}$ a todos los valores de nuestra imagen nacionalsocialista del mundo ${ }^{26}$.

Hoy hay gente que trata de mezclar el pensamiento heideggeriano y la ideología nazi, contando con atizar cenizas que nunca se han apagado definitivamente. Para comprender a qué perversiones de perspectiva lleva una confusión semejante, basta con leer el visceral artículo escrito con ocasión de la publicación del libro de Farias por Rosellina Balbi, titulado «Se questo era un Maestro» ${ }^{27}$. ¿Quizás haciendo alusión al título de Primo Levi ella pretendía borrar la enseñanza de Heidegger y su enrome influjo sobre el pensamiento y la cultura contemporánea o, lo que es lo mismo, más de cincuenta años de filosofía europea? Pregunto: ¿Pero acaso Sartre, que precisamente en 1933 estaba en Berlín y naturalmente había oído hablar de Heidegger, ha dejado de considerar alguna vez a Heidegger como a un Maestro? ¿Y Jaspers? ¿Y Gadamer? ¿Y Derrida? Es curioso que a posteriori se constituya en juez y se escandalice más que quien fue testigo directo de aquellos acontecimientos. Y no se sabe, al fin y al cabo, qué autoridad o qué derecho especial pueda arrogarse Rosellina Balbi, más que Sartre y Jaspers, más que Gadamer y Derrida, para pretender juzgar la enseñanza de aquel gran Maestro que fue Heidegger y que todos ellos, y muchos otros todavía, reconocen. Personalmente me permito seguir creyendo con ellos que Heidegger ha sido uno de los grandes maestros del pensamiento y probablemente el mejor filósofo que ha tenido el siglo xx (que luego el siglo xx haya sido o no un siglo importante para la filosofía, es una cuestión que juzgarán los que vengan después).

En cuanto a Farias, si además de declararse su alumno, hubiese leído también los libros de Heidegger, probablemente se hubiese dado cuenta de la inconsistencia y de la inutilidad de las propias ilaciones. Pero, ¿qué queréis? Ya lo decía Heráclito: «Los perros ladran a quienes no conocen».

26. En la revista Volk im Werden 2 (1934), 247-249.

27. La Repubblica, 24 de octubre de 1987. 
Portofranco: Volvamos a hablar de Hitos y, por una vez, antepongamos a la discusión del significado de los textos finitos una ojeada a los bastidores, al laboratorio del traductor que ha dado - y viene el caso decirlo- nueva vida a la obra. ¿Por qué es tan difícil traducir a Heidegger? ¿Por qué, viceversa, es tan fácil encontrar, en las versiones italianas, traducciones diferentes y a menudo contrapuestas de los mismos términos? ¿Se trata de falta de pericia de los traductores, del alto grado de interpretabilidad del texto o, en el fondo, de su intraducibilidad?

F. Volpi: Heidegger es un chamán de la palabra. Excava en el lenguaje hasta arrebatar a las palabras una confesión filosófica; hace presión sobre los étimos para rescatar conexiones profundas que en la superficie del flujo del discurso no aparecen o no son inmediatamente visibles. Ésta es la razón por la que su escritura, difícil también para un alemán, resulta difícil de traducir a una lengua extranjera, y tanto más a una lengua romance como el italiano, en la que no se puede contar con la presencia de raíces comunes con el alemán. Ésta es la razón por la que quien intenta tal empresa a menudo se encuentra colocado literalmente frente a la intra-ducibilidad. El problema, con el que nos topamos también al traducir a otros pensadores alemanes, es particularmente torturante para el traductor de los escritos de Heidegger, porque Heidegger utiliza la palanca con un trabajo de «etimología especulativa» para obtener de él los conceptos-pilastras de su pensamiento: basta pensar en Ereignis, término que significa corrientemente "acontecimiento", pero que Heidegger entiende también, pensando en la raíz de las palabras, en el sentido de «apropiamiento», por lo tanto de «acontecimiento apropiante», y con el cual indica la peculiar estructura del «acontecer» del ser (en referencia al hombre); y como se sabe, trabaja sobre la misma raíz para sacar toda una serie de conceptos como Enteignis (expropiación), Übereignung (trasmisión), Eignung (apropiación). Otro término clave es Ge-stell, literalmente «bastidor», "trípode»: indica la disposición esencial que caracteriza al mundo de la técnica, en el cual todo es considerado y tratado como artefacto y producto (Herstelltes), olvidando por lo tanto la dimensión de lo que, en cuanto «natural», es por principio sustraído al hacer y al maquinar del hombre, y que no se deja por lo tanto «poner en orden» o "disponer»(bestellen), ni representar (vorstellen) o falsificar (ver-stellen) por el hombre a su voluntad. El Ge-stell es, por lo tanto, aquella disposición en la que se recogen todas las actitudes que en alemán se expresan mediante compuestos de stellen (poner, colocar); en este sentido - pensando a la manera en que términos análogos son expresados (Ge-wissen = con-ciencia $)$ - un calco posible en italiano habría sido "compuesto", en el sentido del conjunto de los modos de poner. Puesto que tal calco no se podía proponer, en Hitos he adoptado como traducción «instalación», vocablo que trasmite el sentido que comúnmente tiene el término alemán, y en el cual se puede advertir la oposición a lo que es «por naturaleza». Pero análogas dificultades se encuentran continuamente en el texto heideggeriano.

La traducción de Hitos presenta también dificultades particulares por el hecho de que el volumen comprende ensayos muy densos y escritos en un arco de tiempo muy amplio, más de tres décadas, y en la traducción se trata de mantener una unidad terminológica que, al mismo tiempo, tenga en cuenta las variaciones terminológicas y conceptuales que en tal lapso de tiempo han tenido lugar. Por 
dar un ejemplo: el fenómeno del «cuidado» está notoriamente tematizado en Ser y tiempo mediante el concepto de Sorge, pero en los escritos juveniles se encuentra por el contrario el término Bekümmerung. Todos los problemas terminológicos esenciales los he explicado brevemente en el Glosario que se añade como apéndice a Hitos, en el cual justifico las traducciones adoptadas y explico, donde es necesario, los motivos de las elecciones realizadas y de los matices de significado (que Heidegger confiere a veces también sólo mediante una grafía particular).

En cuanto a la diversidad de elecciones adoptadas por los traductores italianos de Heidegger, diré que la cosa es natural, y precisamente está ligada a la esencia misma de la traducción. Al trasladar, de hecho, de un lenguaje a otro un sentido que se presupone uno, siempre estamos sometidos al hecho de que puede ser adoptada una y solamente una de las múltiples posibilidades lingüísticas por medio de las cuales es posible traducir aquel sentido. Pero me parece que se ha formado en Italia, gracias a los muchos estudiosos de Heidegger que trabajan en nuestro país, una cierta koiné, una plataforma terminológica generalmente aceptada y compartida. No sé, pero pienso en un concepto como «estar-ahí» (esserci), con el cual el malogrado Chiodi tradujo, recalcándolo, el sentido que Heidegger da al término alemán Dasein (que se suele traducir por el contrario como «existir» o «existencia»): eso no sólo es aceptado ya por todos, sino que ha entrado en el lenguaje filosófico y viene comprendido y empleado también por los no especialistas de Heidegger.

Quisiera añadir también otra observación a propósito del trabajo de traducción, tal y como se viene haciendo en Italia. Como se sabe éste es uno de los trabajos más ingratos y peor remunerados, y quizás por eso es a menudo desarrollado de una manera no adecuada. Falta además un control suficiente sobre las traducciones. De manera que no es un caso raro asistir a la publicación de traducciones plagadas de errores y absolutamente nada fiables, incluso en editoriales famosas. Esto ha sucedido, desgraciadamente, también con ciertos escritos de Heidegger, traducidos quizás por estudiosos altamente cualificados y acreditados, pero que a veces non están a la altura de su fama. Si se tiene la paciencia de controlar la traducción del ensayo De la esencia del fundamento, publicado por UTET, y ahora vuelto a traducir ex novo en Hitos, se encontrarán numerosísimos errores. Pero esto no es todavía nada en comparación con lo que ha sucedido en el caso de la «traducción» de De la esencia de la verdad, publicado por un amigo mío para la editorial La Scuola de Brescia: puedo decir — también porque se trata de un amigo, y sé que puedo decirlo sin que me guarde rencor- que esta traducción no es una traducción, sino otra cosa: hay ante todo innumerables errores sobre el alemán más común y elemental; en diversas frases el sentido se cambia o se modifica arbitrariamente, haciendo decir a Heidegger cosas que nunca ha dicho; en algún otro punto hay expresiones o proposiciones enteras que en alemán no existen; otras que sí están en alemán no se encuentran en la «traducción», y así sucesivamente. Naturalmente esto es un caso límite, pero es un indicio de un problema más general.

Portofranco: Heidegger es ciertamente un autor difícil. Sin embargo, lo que podemos definir como su «estilo de pensamiento» mantiene una fascinación muy particular, incluso para quien conoce poco las grandes cuestiones de la filosofía; 
esto vale en particular para Hitos. ¿Cuáles son las razones de esta fascinación que supera los límites disciplinares de la filosofía?

F. Volpi: Es evidentemente el hecho de que los problemas que Heidegger plantea y sobre los cuales piensa a fondo no son los problemas disciplinares de los filósofos de profesión, sino que son problemas que atañen a un destino que nos implica a todos. Naturalmente, Heidegger se ha ocupado y ha escrito también de cuestiones filosóficas específicas, y algunos textos suyos, como por ejemplo su interpretación del concepto de physis en Aristóteles, requieren un conocimiento de la filosofía y de su historia, por lo tanto una larga preparación, para poder ser comprendidos y desentrañados a fondo. Pero en otros muchos escritos, como en la Carta sobre el humanismo o en la respuesta a Ernst Jünger contenidos en Hitos, Heidegger habla de cuestiones fundamentales de nuestra época de un modo que, si estamos dispuestos a seguirlo en el pensar que él pone en acto, todos podemos comprender. Y de estos problemas, de nuestra situación, nos ofrece uno de los análisis más clarividentes. Por esto, su pensamiento, que desde finales de los años veinte no ha dejado de influir, alarga todavía su sombra sobre el pensamiento contemporáneo. Nos guste o no, es uno de los pasos obligados para quien quiera comprender. Ahí está como un peñasco solitario que las olas del debate contemporáneo acarician, sin conseguir desplazarlo.

\section{LAS LUCES Y LA LARGA SOMBRA DE NIETZSCHE ${ }^{28}$}

$$
\text { Franco Volpi }
$$

Con el pretexto de la traducción adelphiana del libro de Isaiah Berlin Controcorrente, el domingo 3 de diciembre ha intervenido Eugenio Scalfari planteando una cuestión que ha vuelto a ser actual: ¿Qué es la ilustración? Es decir: ¿nuestra época es ilustrada? Conocemos la célebre respuesta de Kant, publicada exactamente el 5 de diciembre de 1784:

Ilustración es la salida del hombre de un estado de minoría de edad imputable a él mismo. Minoría de edad es la incapacidad de servirse del propio intelecto sin la guía de otro. Es imputable esta minoría de edad a él mismo si su causa no está en un defecto de la inteligencia, sino en la falta de resolución y coraje de servirse del propio intelecto sin la guía de otro.

Si esto es la ilustración hace bien Scalfari en lamentar que nuestra época contemporánea esté todavía poco iluminada y que las Luces ya no estén de moda entre pensadores e intelectuales, entre las eminencias grises y los maestros del pensamiento de la cultura contemporánea, orientados preferentemente hacia los «románticos» y su imaginería mítica y simbólica, cuyas degeneraciones políticas han p. 52 .

28. «I lumi e l'ombra lunga di Nietzsche», publicado en La Repubblica, 8 de diciembre de 2000, 
marcado profundamente el siglo xx. Se comprende, por lo tanto, la preocupación de Scalfari cuando advierte de que hasta el corazón de un intelectual de indiscutida pertenencia a la democracia liberal como Berlin lucha más por los románticos que por los filósofos de las Luces. Scalfari recuerda por eso las conquistas ideales de la ilustración, los principios que ha fundado y a los que hoy no puede uno no referirse: libertad de pensamiento y expresión, inviolabilidad del individuo y de sus derechos fundamentales, igualdad, solidaridad. Se debe reconocer a Scalfari el mérito de haber captado la importancia del libro de Berlin, de quien de otra manera sólo pocos especialistas habrían hablado, y de haberlo conectado a un problema filosófico fundamental, el de los valores que inspiran nuestra idea de humanidad y que están en la base de toda sociedad democrática moderna.

No sé de qué parte lucharía el corazón de Berlin. Imagino que, más allá de sus inclinaciones personales, como refinado historiador de las ideas tuviese la intención de poner en discusión algunos estereotipos de la historiografía tradicional, mostrando cómo la edad de las Luces no presenta sólo fulgor, sino que está también surcada por algunas venas oscuras que al final se han revelado determinantes. Algo que Berlin ha tratado de mostrar también en otros dos libros, traducidos por Adelphi: El amigo del Norte, una aguda interpretación de Hamann, y El leño retorcido de la humanidad, expresión que toma prestada de Kant para expresar un pesimismo desencantado hacia los nobles y optimistas ideales de la antropofilia. Pero turbias vetas se encuentran, además de entre las nórdicas nieblas de Königsberg, también en los grandes filósofos del Julio francés. Por ejemplo, en Rousseau, pensador brillante y visionario, cuyas ideas pedagógicas y políticas ofrecen rasgos fanáticos, por no decir totalitarios, que inspiran el Terror no menos que la Ilustración. Por otra parte, no todo es irracionalismo en la vertiente romántica: en el corazón de la Alemania filosófica de entonces, Hölderlin, Hegel y Schelling plantaron un árbol de la libertad en el Stift de Tubinga, donde eran confabuladores, para celebrar el aniversario de la Bastilla y de los ideales de la libertad que el acontecimiento simbolizaba. Pero éste no es el punto. La distinción de Scalfari es típicamente ideal, no histórica, y el problema que él plantea es de principio: ¿cuál es el paradigma de pensamiento que hay que asumir hoy? ¿El ilustrado de la razón o el romántico de la imaginación? La respuesta es clara: «El mundo moderno sufre no por un exceso, sino por un dramático déficit de racionalidad». Sacrosantas palabras que hay que compartir en todo. Pero si es verdad que el paradigma ilustrado-racionalista ha llevado a conquistas civiles irrenunciables, es por otra parte verdad que la Razón se ha reducido cada vez más a mera razón instrumental, demostrándose incapaz de gobernar aquella fuerza ciega que Nietzsche llama voluntad de poder. Adorno y Horkheimer hablaban de una «dialéctica de la ilustración» que en las modernas sociedades de masas termina por arruinarse en su contrario. Antes que ellos, Goya representaba en sus bosquejos el sueño de la razón que produce monstruos. Por lo tanto la racionalidad de la que la edad moderna carece no es la instrumental, que la tecnociencia nos proporciona más bien en abundancia, sino la sustancial, capaz de fundar identidad y recursos simbólicos compartidos. Por esta función lo sagrado, el mito, lo simbólico, con sus potentes imágenes que los románticos habían cultivado, son recursos demasiado importantes para ser dejados a merced del irracionalismo. Ni hay que adherirse necesariamente a la contraposición entre Cultura y Civilización, ni quizás poner en juego la una con 
la otra, como hacía Thomas Mann cuando afirmaba que «la germanidad es cultura, alma, libertad, arte y no civilización, sociedad, derecho de voto, literatura». Si recuerdo bien, precisamente Scalfari ha criticado con agudeza tales hipótesis discutiendo sobre estas páginas las Consideraciones de un impolítico. Pero el verdadero nudo es Nietzsche. En él se concentra simbólicamente el problema de la crisis de la razón con los temblores que produce. El fuego prendido por él arde hoy por todas partes. Nietzsche afirmó que la razón no es otra cosa que un frágil instrumento orgánico de autoconservación, Dios una hipótesis para reducir la contingencia del caos, la verdad un escorzo perspectivo, una especie de error sin el cual el hombre no podría vivir. Del mismo modo que no hay hechos, sino sólo interpretaciones, que son funcionales para la vida y para su conservación. Sirviéndose de la sutil navaja "genealógica» ha deconstruido los edificios de la razón, acelerando la desvalorización de los valores y el nihilismo Y su descripción ha tenido un carácter operativo, contribuyendo a producir la crisis que se describía. En este sentido, Gottfried Benn pensaba explicar hasta la coherente fragmentariedad de la obra Nietzscheana: «Ahora comprendo», afirmaba, «por qué Nietzsche escribía por medio de aforismos. Quien ya no ve conexiones, ni ninguna traza de un sistema, puede proceder todavía sólo por episodios». Ésta es la grandeza trágica de Nietzsche. Sin embargo, de manera distinta que Benn, podemos pensar que sus aforismos no son fragmentos inconexos, sino toques cromáticos de una composición puntillista que deja ver la totalidad. Tomemos por ejemplo nuestra idea de humanidad y los valores que encierra. Ya Kant denunciaba la insuficiencia de uno de los pilares sobre los que se apoyaba, la definición griega del hombre como animal racional. Ni la animalitas ni la rationalitas bastan para constituir la humanitas del hombre. Se prefiere aquella que él llamaba la spiritualitas o personalitas, concepto basado en el otro pilar de la tradición, el cristianismo. Desde hace tiempo, sin embargo, la ciencia y la técnica acrecientan nuestro saber y nuestra capacidad de intervención sobre la entidad «hombre» de una manera que entra cada vez más en conflicto con la fe cristiana. Hoy nos encontramos en una "crisis antropológica». Pues bien, en su lapidaria afirmación de que el hombre es «el animal todavía no definido», Nietzsche la ha anticipado: el ser humano nos ha hecho comprender que está expuesto y abierto a dos extremos igualmente peligrosos para su comportamiento, la espantosa naturaleza de sus pulsiones y el carácter ilimitado de su razonar. Nosotros, en la crisis antropológica diagnosticada por Nietzsche, debemos preguntarnos: ¿tenemos una idea del hombre compartida, una antropología adecuada a los problemas que la globalización y la multiculturalidad plantean? Ésta es la cuestión filosófica que veo emerger de la intervención de Scalfari: una cuestión fundamental que es afrontada con la debida paciencia, de la que se había armado prudentemente Kant cuando afirmaba que «ilustrar» a un individuo es fácil, pero que «ilustrar» a una época es una empresa casi desesperada.

Traducción de Luis Enrique de Santiago Guervós Universidad de Málaga 